

\section{Heavy Metals}
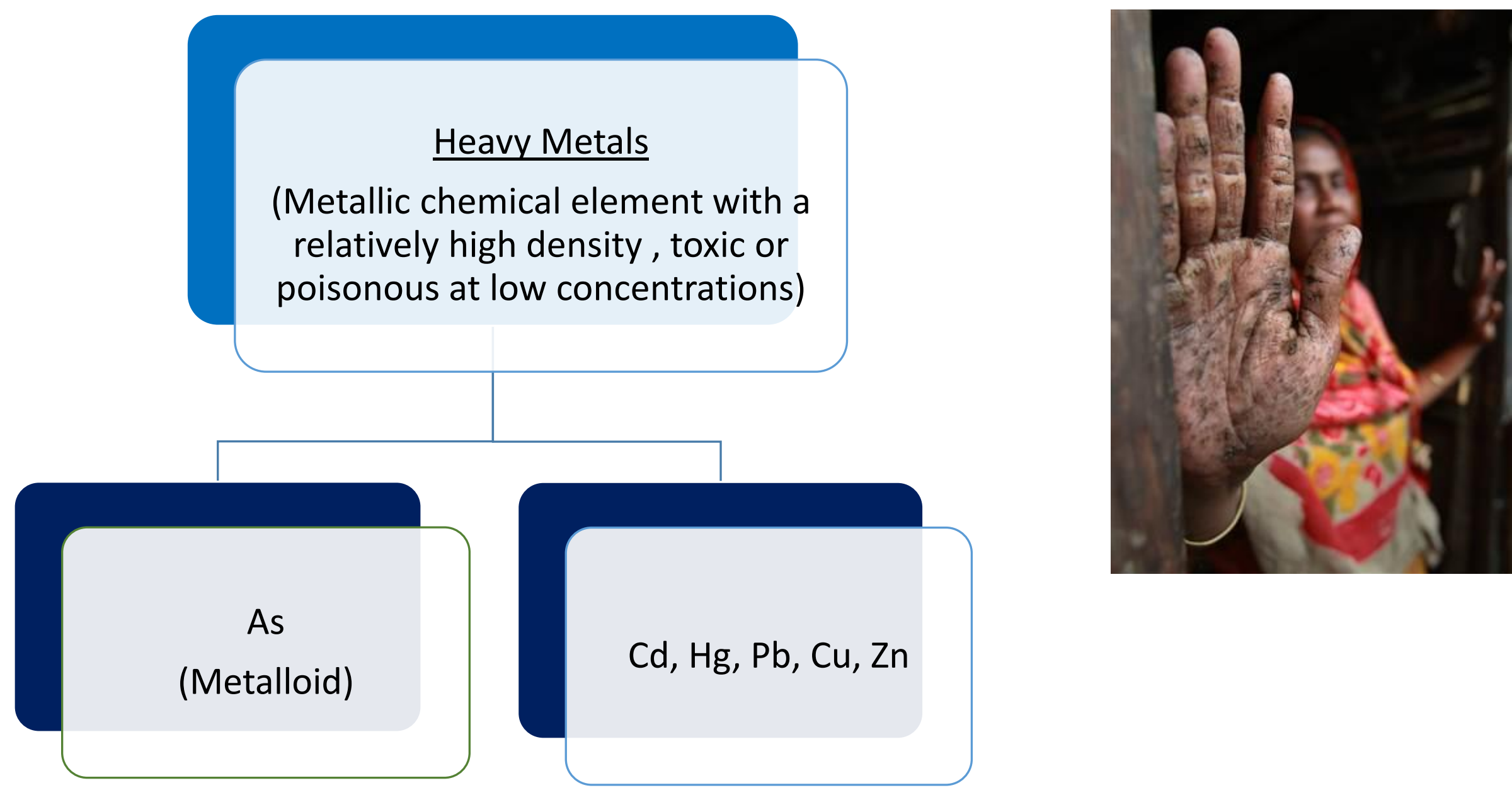

- Maximum Contaminant Levels (ppb): $\mathrm{As}=10, \mathrm{Hg}=2, \mathrm{Cd}=5, \mathrm{~Pb}=15$ 


\section{Synthetic Dithiols (Ligands) to Remove heavy metals from Water}

1) B9 $=N, N^{\prime}$-bis (2-mercaptoethyl)isophthalamide

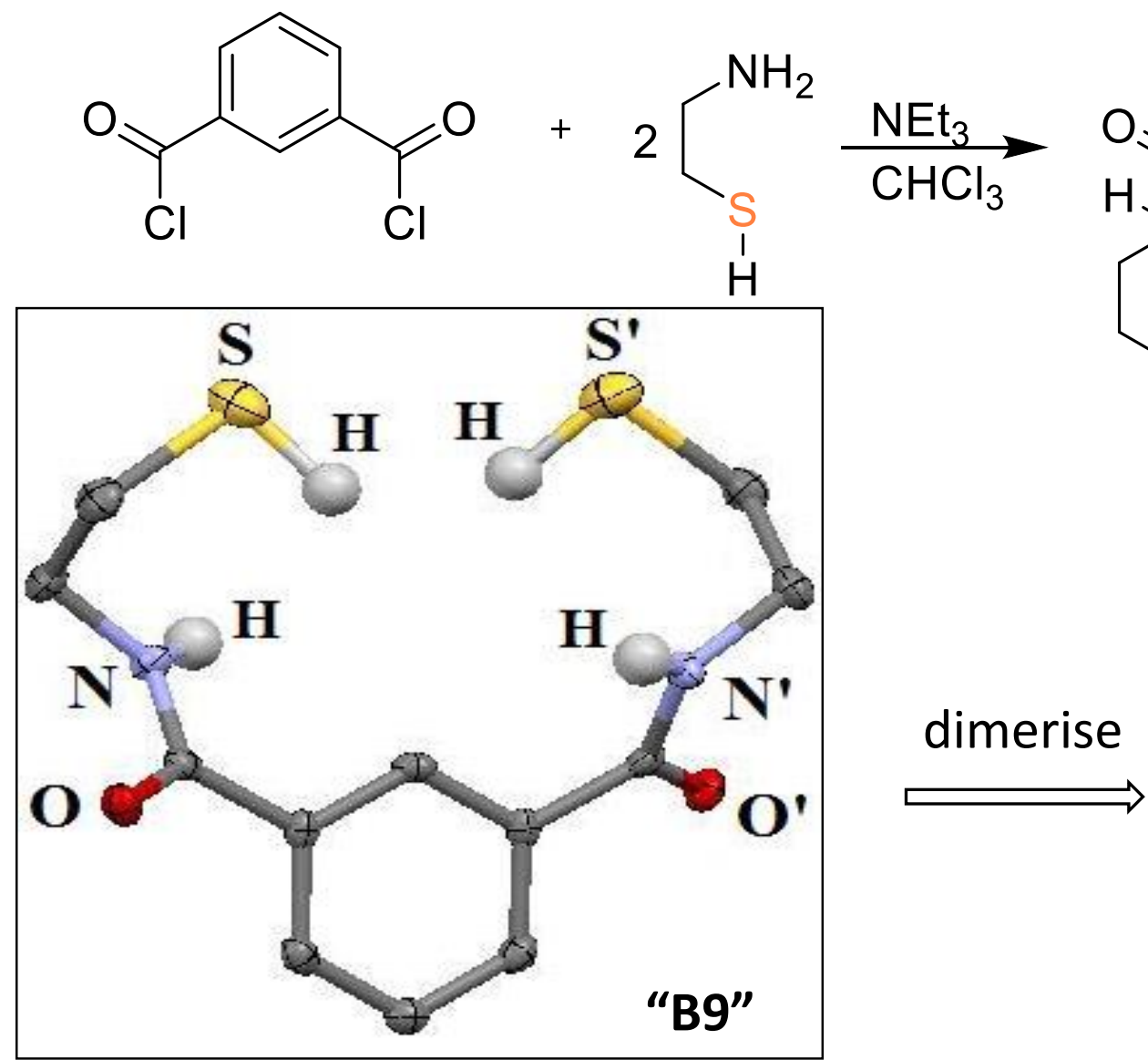<smiles>O=C(NCCS)c1cccc(C(=O)NCCS)c1</smiles>

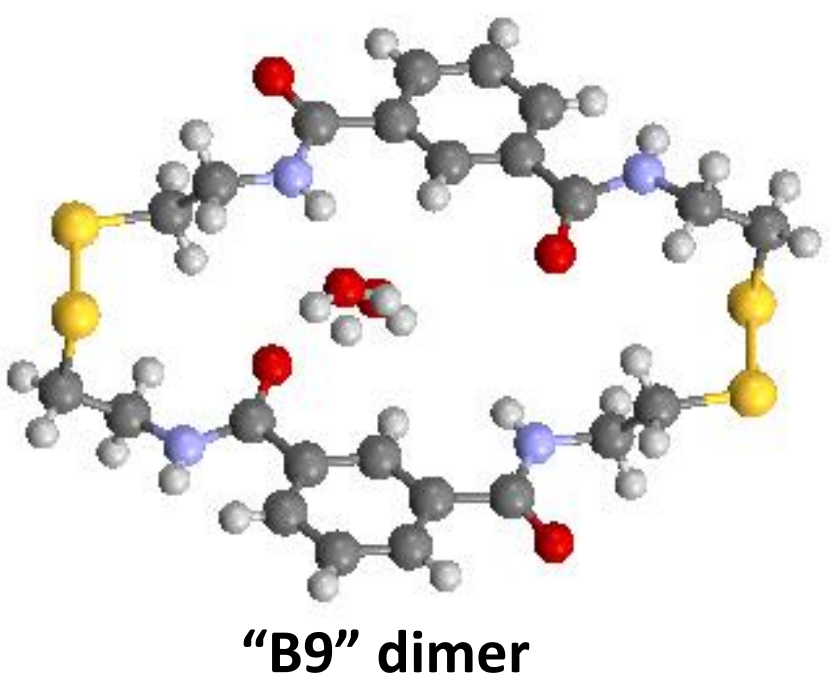




\section{Published L-M Compounds; B9 as Ligand}

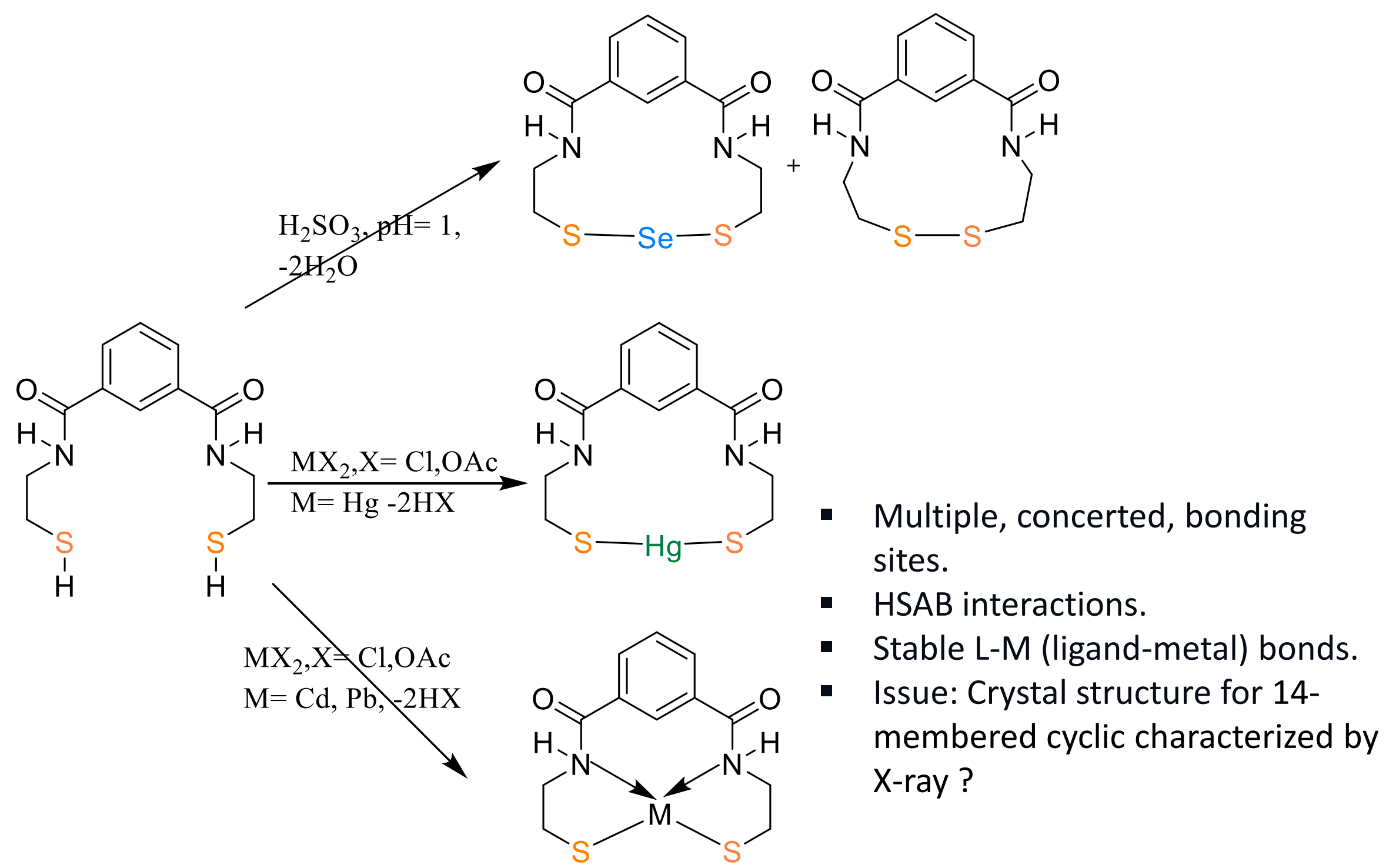

Burriss, Daniel, et al. "Removal of selenite from water using a synthetic dithiolate: an experimental and quantum chemical investigation." Inorganic chemistry 53.8 (2014): 4010-4021

Zaman, K. M., et al. "Cd, Hg, and Pb compounds of benzene-1, 3-diamidoethanethiol (BDETH2)." Inorganic chemistry 46.6 (2007): 1975-1980., 


\section{Synthetic Dithiols (Ligands)}

1) $B 9$

2) $A B 9$

3) MB9

4) $\mathrm{EB} 9$

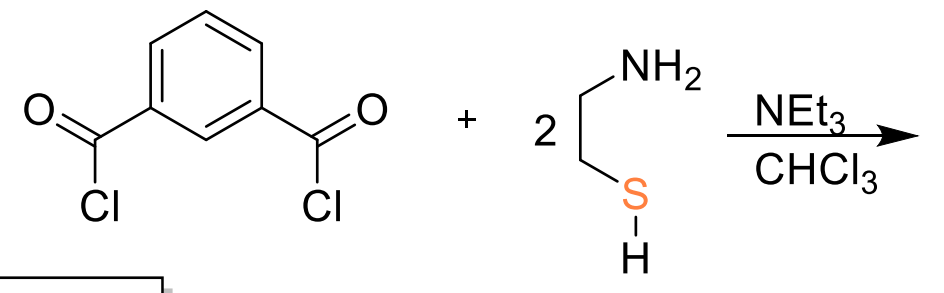<smiles>O=C(NCCS)c1cccc(C(=O)NCCS)c1</smiles>
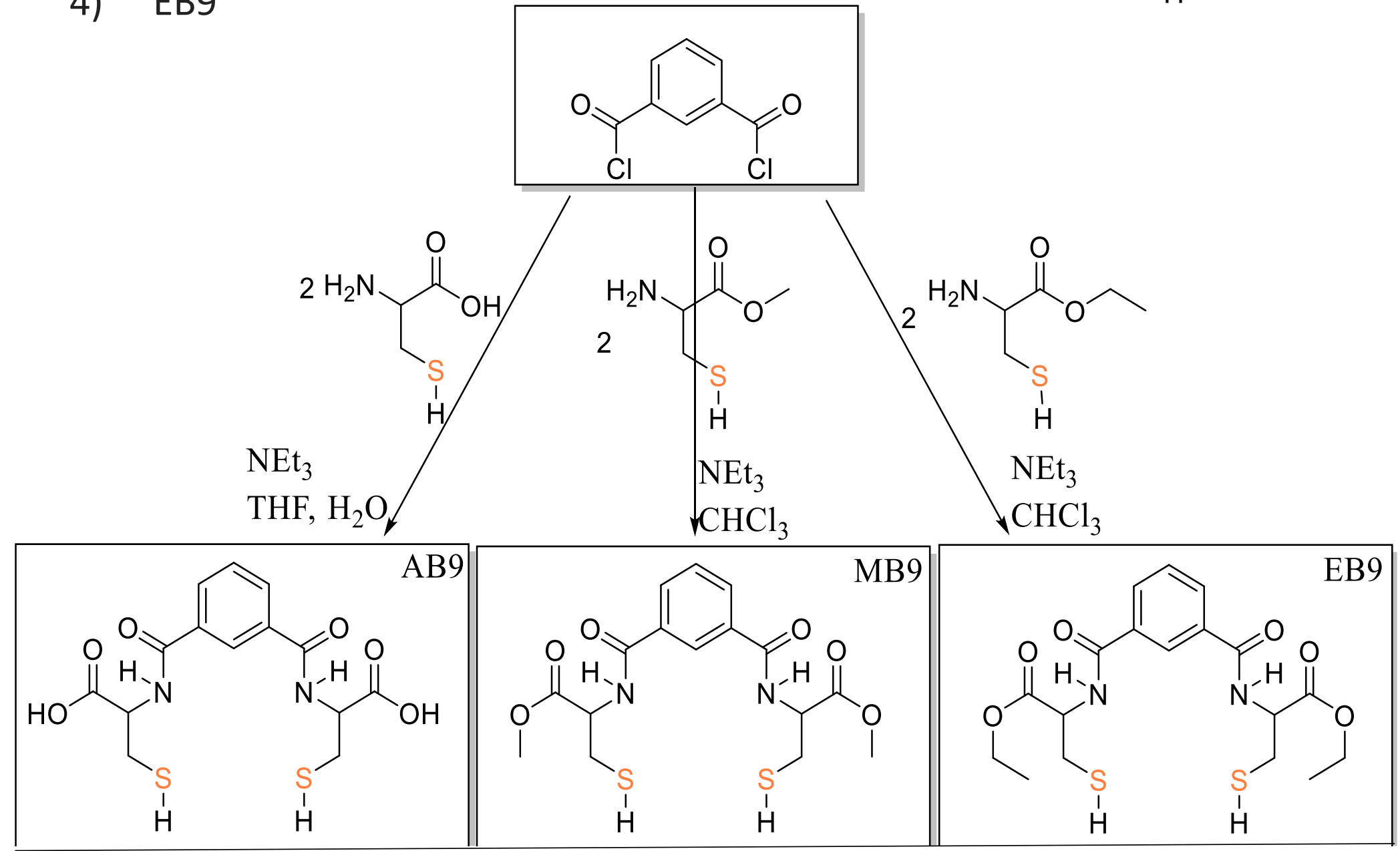


\section{Goals of Project 1: Synthetic Dithiols (Ligands) to Remove heavy metals from Water}

1. To expand the range of compounds capable of effective metal precipitation.

2. To gain L- M having similar bonding possibilities as B9.

3. To include new functionality into compounds (using carboxylic acid and esters).

4. To prepare more soluble L-M compounds for X-ray crystallographic analysis.

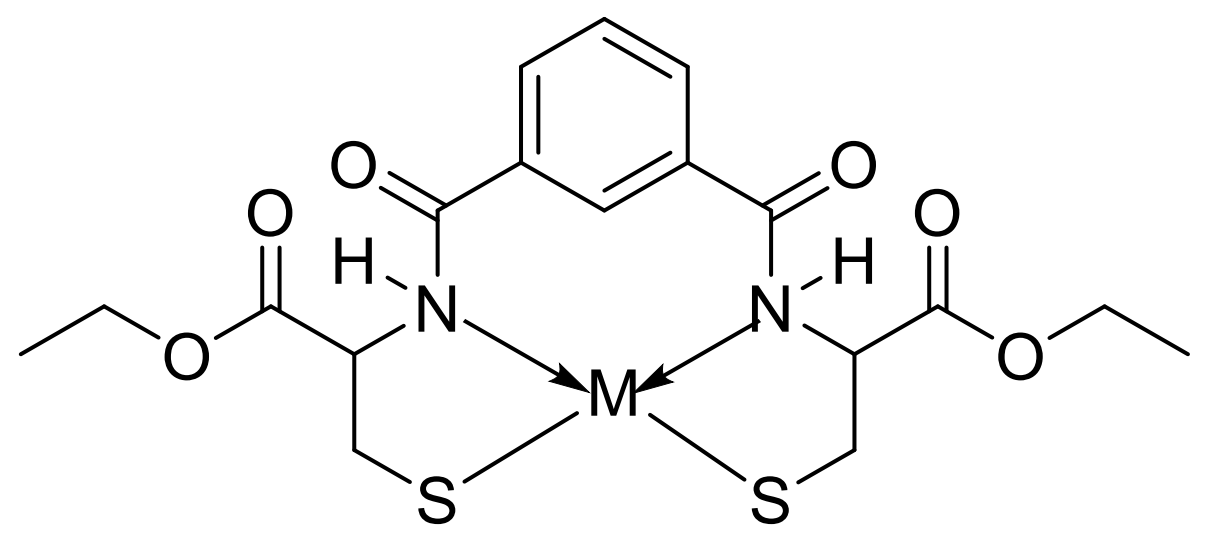




\section{$\%$ Removal of Heavy Metals}

\begin{tabular}{cccccc}
\hline L-M ratio & $\begin{array}{c}\text { Original metal } \\
\text { conc. }(\mathrm{ppm})\end{array}$ & $\begin{array}{c}\text { Ligand } \\
\text { dosage }(\mathrm{g})\end{array}$ & $\begin{array}{c}\text { Time }(\mathrm{h}) \\
\mathrm{B} 9: \mathrm{Pb}=1: 1\end{array}$ & $\begin{array}{c}\text { Solution } \\
\mathrm{pH}\end{array}$ & $\begin{array}{c}\text { Maximum \% } \\
\text { metal removal }\end{array}$ \\
\hline $\mathrm{B} 9: \mathrm{Hg}=1: 1$ & 50.00 & 0.0069 & 5 & 4 & 99.9 \\
$\mathrm{~B} 9: \mathrm{As}=1: 2$ & 50.00 & 0.0046 & 5 & 5.93 & 99.7 \\
$\mathrm{EB9}: \mathrm{As}=1: 1$ & 50.00 & 0.0647 & 5 & 6.97 & 95.97 \\
$\mathrm{EB9}: \mathrm{Cd}=1: 1$ & 50.00 & 0.0110 & 5 & 8.3 & 82.23 \\
$\mathrm{EB9}: \mathrm{Pb} 1: 1$ & 50.00 & 0.0277 & 5 & 6.54 & 49.04 \\
$\mathrm{MB9}: \mathrm{Pb}=1: 1$ & 50.00 & 0.0046 & 5 & 6.65 & 83.92 \\
$\mathrm{MB9}: \mathrm{Cd}=1: 1$ & 50.00 & 0.0053 & 5 & 8.57 & 64.83 \\
\hline
\end{tabular}




\section{Goals of Project 2: Thiol Coupled Magnetic Nanoparticles (MNPs) for the Removal of As(III)}

Removal of As(III) from the global water supply:

a) Dithiol compound (AB9) that forms strong As-S covalent bonds to As(III),

b) Pendant carboxylate groups on AB9 for attachment to a silica surface with pendant amines (referred to simply as "silica"),

c) Attachment of $A B 9$ to the silica surface of a magnetic nanoparticle (MNP) to create a new composite material, $\mathrm{AB} 9-\mathrm{SiO}_{2}-\mathrm{Fe}_{3} \mathrm{O}_{4}$,

d) Covalent bonding of arsenite in water to form, $\mathrm{As}$ (III)-AB9-SiO${ }_{2}-\mathrm{Fe}_{3} \mathrm{O}_{4}$ (simplified to As(III)-AB9@MNP,

e) Magnetic separation of As(III)-AB9@MNP from water

Can be achieved.

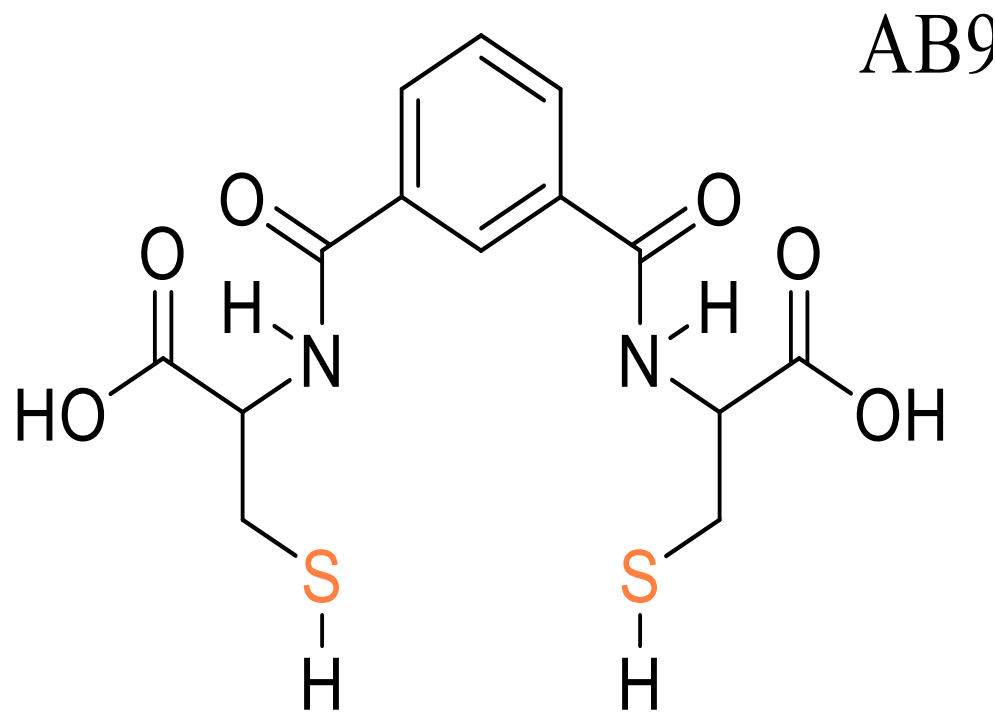


Thiol Coupled Magnetic Nanoparticles (MNPs) for the Removal of As(III)

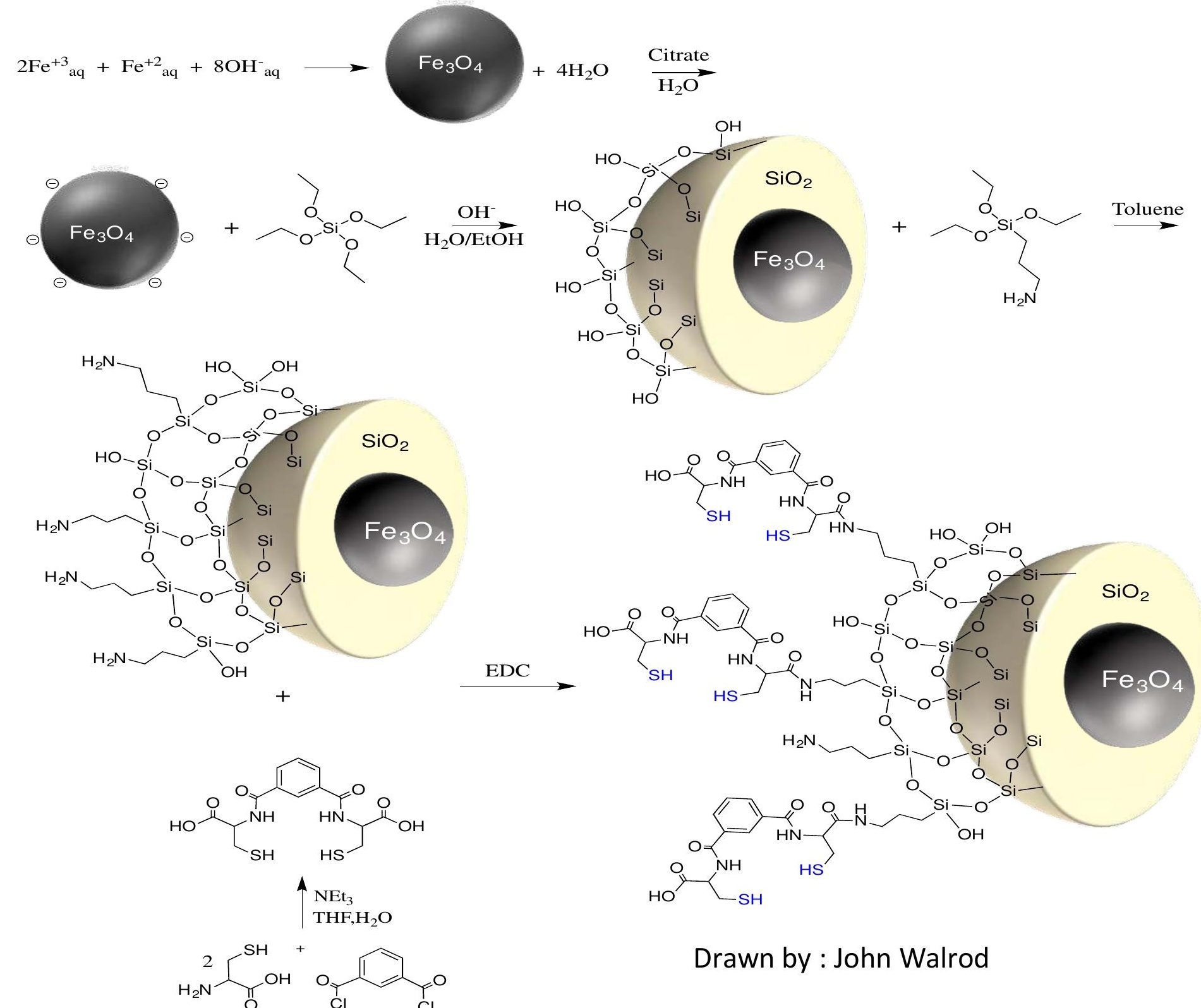




\section{Immobilization of $\mathrm{As}(\mathrm{III})$}

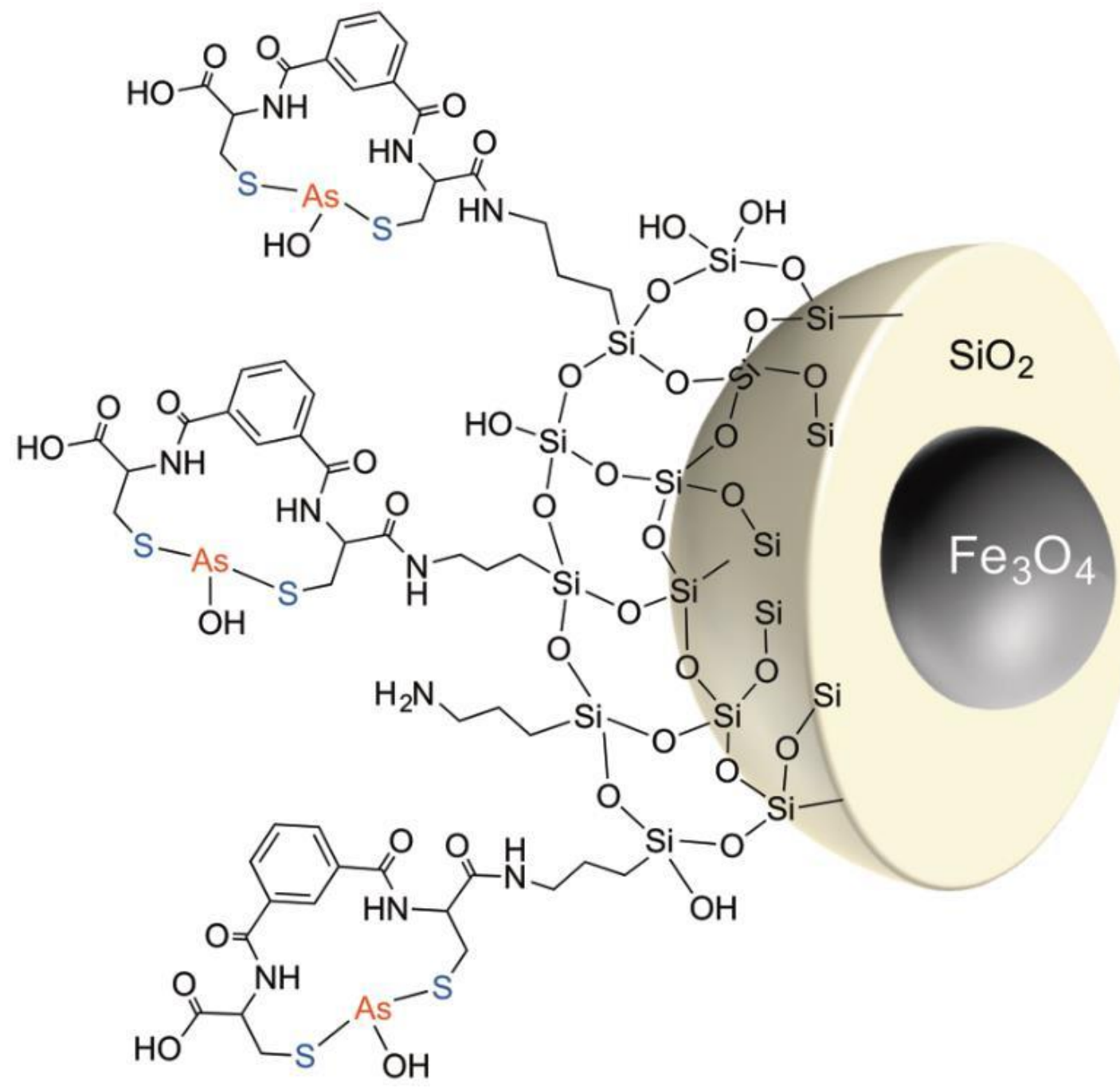

- Form strong covalent As-S bonds

- Optimal proposed split view of AB9@MNPs after As(III) removal 


\section{ICP-OES Results for aqueous As(III) Removal with AB9@MNP}

\begin{tabular}{ccccccc}
\hline Sample & $\begin{array}{c}\mathrm{pH} 5 \\
\text { As (ppb) }\end{array}$ & $\begin{array}{c}\% \\
\text { Removal }\end{array}$ & $\begin{array}{c}\mathrm{pH} \mathrm{7} \\
\text { As (ppb) }\end{array}$ & $\begin{array}{c}\% \\
\text { Removal }\end{array}$ & $\begin{array}{c}\mathrm{pH} 9 \\
\text { As (ppb) }\end{array}$ & $\begin{array}{c}\% \\
\text { Removal }\end{array}$ \\
\hline $\begin{array}{c}\text { As (III) } \\
\text { stock }\end{array}$ & $198 \pm 4$ & - & $207 \pm 2$ & - & $209 \pm 3$ & - \\
$0.1 \mathrm{~g}$ & $32 \pm 1$ & 85 & $27 \pm 9$ & 89 & $25 \pm 5$ & 88 \\
$0.2 \mathrm{~g}$ & $<10$ & $>95$ & $<10$ & $>95$ & $<10$ & $>95$ \\
\hline
\end{tabular}




\section{WhyAB9@MNPs?}

- Made out of non-toxic, earth-abundant elements,

- Rapid magnetic separation allowing an effective, affordable means of providing arsenic-free drinking water to at-risk populations around the world

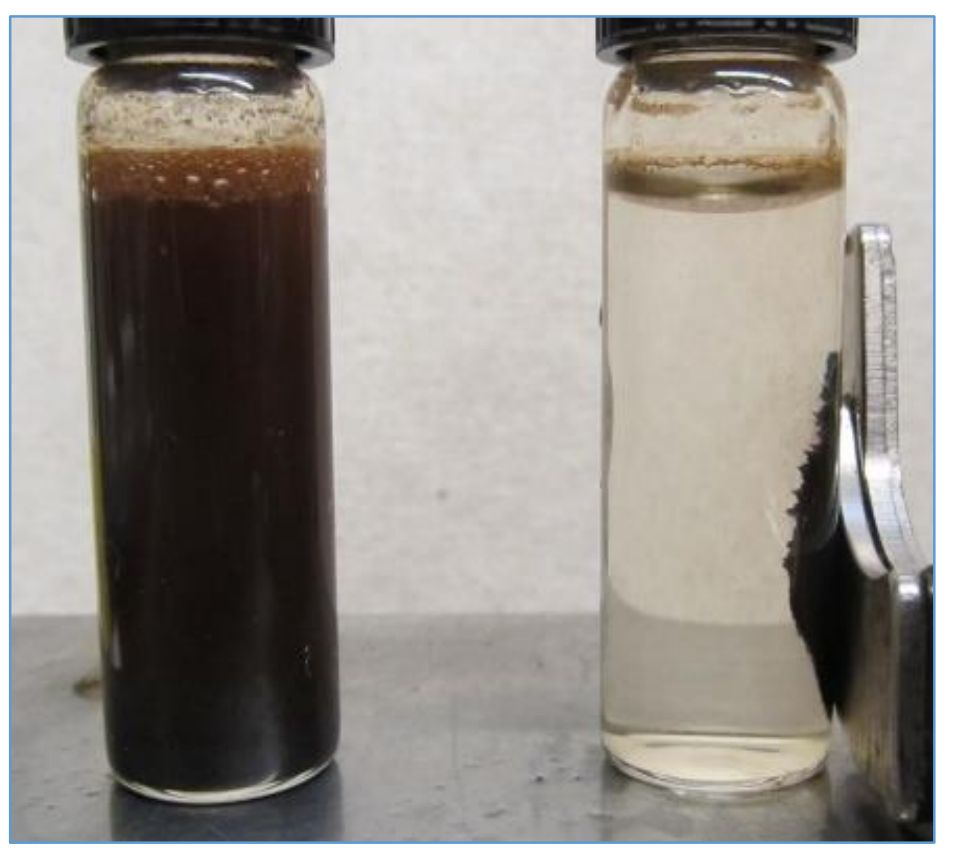

Dispersed AB9@MNPs and magnetically separated AB9@MNPs using computer hard drive magnets 


\section{Conclusions}

- Soft heavy metals can be removed using synthesized compounds.

- Amorphous nature, low solubility consistence with polymeric nature of compounds rather single molecular; preferably coordination polymers.

- MOF may form: geometrically well-defined structure with strong bonding providing robustness, linking units that are available for modification by organic synthesis'

- AB9@MNPs can be used to remove As(III) from water

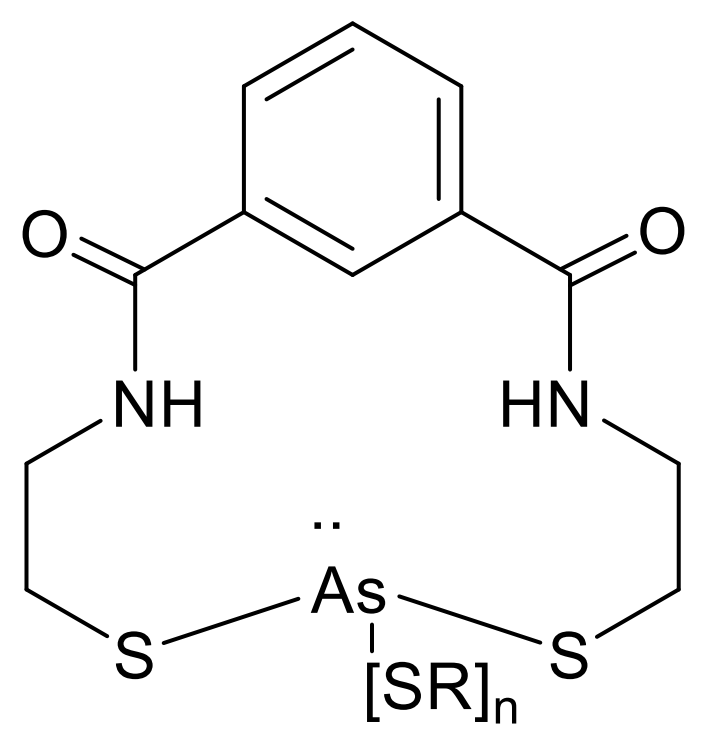

$\left[\mathrm{Bg}_{3} \mathrm{As}_{2}\right]_{\mathrm{n}}$ 


\section{Acknowledgment}

Advisor : Dr. David Atwood

Former group members : Dr. Daniel Burriss

Dr. John Hamilton Walrod

UK ERTL : Megan Combs

UK XRD Facility : Mining Engineering UKY.

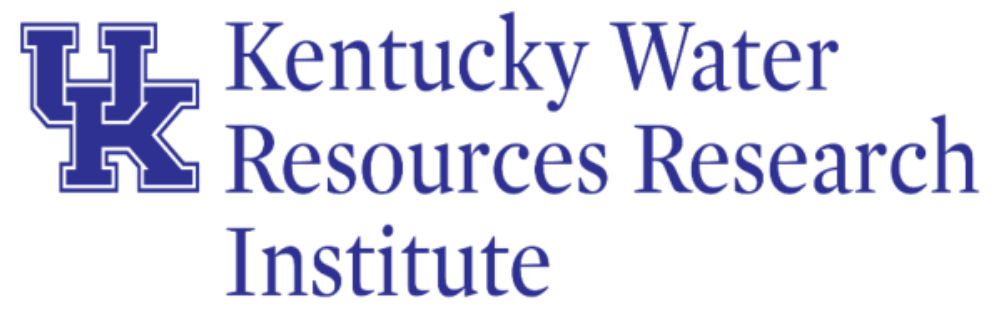

